УДК 338.262

08.00.00 Экономические науки

ФАКТОРНЫЙ АНАЛИЗ ВНЕШНЕЙ И
ВНУТРЕННЕЙ СРЕДЫ НАУКОЕМКОГО
ПРЕДПРИЯТИЯ НА ПРИМЕРЕ
ОТЕЧЕСТВЕННОЙ РАКЕТНО-
КОСМИЧЕСКОЙ ПРОМЫШЛЕННОСТИ *

Славянов Андрей Станиславович

Кандидат экономических наук, доцент

Московский государственный технический университет им. Н.Э. Баумана,

Москва, Россия

aslavianov@mail.ru

Хрусталёв Юрий Евгеньевич

Кандидат экономических наук, генеральный директор

ООО «Трасса», Москва, Россия

KhrustalevYuE@yandex.ru

В работе выявлены и исследованы основные факторы, оказывающие влияние на инновационное развитие отечественного наукоемкого сектора экономики. Авторы выделили две группы факторов - внутренние и внешние, определили их состав и взаимосвязь. В работе внимание уделено одному из сегментов наукоемкого рынка продуктов и услуг космической деятельности. В послевоенный период Россия прочно удерживала лидерство практически на всех направлениях отрасли, однако, экономические и политические реформы активизировали негативное воздействие финансово-экономических факторов, которые существенно затормозили технологическое развитие космической отрасли. В работе исследуется влияние экологических, технологических, финансово-экономических и других факторов, влияющих на развитие наукоемких предприятий. Построена графическая и экономико-математическая многофакторная модель инновационного развития наукоемких предприятий, задействованных в реализации космических программ. Методами экспертных оценок было определено влияние каждого фактора на развитие направлений космической деятельности: - производство средств запуска, космических аппаратов, наземной космической техники и оказание услуг. Полученные оценки влияния факторов найдут применение при формировании программ инновационного
UDC 338.262

Economic sciences

\section{FACTOR ANALYSIS OF EXTERNAL AND \\ INTERNAL ENVIRONMENT OF A SCIENTIFIC ENTERPRISE ON THE EXAMPLE OF THE DOMESTIC ROCKET AND SPACE INDUSTRY}

Slavyanov Andrey Stanislavovich

Candidate of economical sciences, docent

Bauman Moscow State Technical University,

Moscow, Russia

aslavianov@mail.ru

Khrustalev Yurii Evgenievich

Candidate of economical sciences, general director

«Trassa», Moscow, Russia

KhrustalevYuE@yandex.ru

The main factors influencing the innovative development of the domestic science-intensive sector of the economy, were identified and studied in the work. The authors singled out two groups of factors, internal and external, determining their composition and interrelationship. The paper focuses on one of the segments of the knowledge-intensive market of products and services - space activities. In the postwar period, Russia firmly maintained leadership in virtually all areas of the industry, however, economic and political reforms intensified the negative impact of financial and economic factors, which significantly retarded the technological development of the space industry. The paper studies the influence of environmental, technological, financial, economic and other factors affecting the development of knowledgebased enterprises. A graphical and economicmathematical multi-factor model for the innovative development of knowledge-intensive enterprises involved in the implementation of space programs is constructed. The methods of expert assessments determined the influence of each factor on the development of space activities: - the production of launch vehicles, space vehicles, ground-based space technology and the provision of services. The received estimations of influence of factors will find application at formation of programs of innovative development of the high technology enterprises

\footnotetext{
* Работа подготовлена при финансовой поддержке РФФИ (проект №17-06-00373 А)
} 
развития наукоемких предприятий

Ключевые слова: КОСМИЧЕСКИЕ УСЛУГИ, РАКЕТНО-КОСМИЧЕСКАЯ ПРОМЫШЛЕННОСТЬ, ПРОГРАММЫ ИННОВАЦИОННОГО РАЗВИТИЯ, КОНКУРЕНТОСПОСОБНОСТЬ
Keywords: SPACE SERVICES, SPACE-ROCKET INDUSTRY, PROGRAMS OF INNOVATIVE DEVELOPMENT, COMPETITIVENESS.

\section{Doi: 10.21515/1990-4665-132-059}

Изучение факторов, влияющих на инновационное развитие предприятий и промышленности страны в целом является важнейшим направлением экономических исследований. Применение экономических моделей в исследованиях позволяет определить зависимости между различными элементами модели и оценить влияние различных факторов на конечный результат.

Наиболее известной многофакторной моделью принято считать производственную функцию Кобба-Дугласа, в которой основными факторами считаются труд $(L)$ и капитал $(K)$. Остальные факторы учитываются коэффициентом пропорциональности $(A)$. Совокупный выпуска $(Y)$ определяется по формуле:

$Y=A K^{a} L^{b}$

где $a$ и $b$ коэффициенты эластичности, рассчитываемые, как и коэффициент $A$ эмпирическими методами. Коэффициент $A$ учитывает масштабы производства, уровень организации и другие факторы. Производственная функция Кобба-Дугласа показывает, что для увеличения выпуска продукции необходимы инвестиции и приток новой рабочей силы. В современных условиях обострения конкурентной борьбы, увеличение выпуска оправдано только при наличии рынков сбыта, на которых уверенно может чувствовать себя предприятие, периодически обновляющее свою продукцию. Внедрение новых технологий, повышение квалификации работников позволяет экономить ресурсы, снижать себестоимость, что в конечном итоге влияет на цену и конкурентоспособность выпускаемой продукции. Модифицированная http://ej.kubagro.ru/2017/08/pdf/59.pdf 
производственная функция Кобба-Дугласа учитывает влияние научнотехнического прогресса, который задается новым членом $\mathrm{e}^{\mathrm{x}}$ и имеет вид: $Y=A K^{a} L^{b} e^{x}$

На основе производственной функции Кобба-Дугласа было разработано множество модификаций, учитывающих влияние различных факторов. Интерес для исследования представляет производственная функция знаний, учитывающей такой фактор, как затраты на научные исследования и разработки. В модели, разработанной Полом Ромером [12], вся экономика разделена на два сектора: производства и НИР (научных исследований и разработок). Сектор производства не располагает собственными исследовательскими мощностями и закупает технологии в исследовательском секторе.

$Z=A \cdot L_{z}^{b} \cdot z^{c}$

где $Z$ - новые знания, $z$ - накопленные ранее знания, $L_{z}-$ человеческий капитал, $A-$ коэффициент пропорциональности, $c$ и $b$ коэффициенты эластичности, рассчитываемые, как и коэффициент $A$ эмпирическими методами. Учеными Сибирского отделения РАН в качестве новых знаний были предложен показатель «количество инновационных предприятий», человеческий капитал оценивался численностью работников, занятых НИОКР [1]. Некоторые ученые (Т. Штерцер [2], Р., Крешенци, А, Якс [13] и др.) в качестве зависимой переменной в модели П. Ромера выбирают число патентов ( поданных патентных заявок).

Модель А. Джаффе [14], учитывает географическую близость ученых и исследователей к источникам знаний, к которым он относил научно-исследовательские институты и университеты. Этот фактор дает возможность ученым обмениваться научными результатами, что способствует получению новых знаний. Крупнейший научный центр «Силиконовая долина» в Калифорнии, подтверждает практическую http://ej.kubagro.ru/2017/08/pdf/59.pdf 
ценность данной модели. В России инновационная активность отмечается в регионах, где ощущается влияние крупных университетов мирового уровня, а именно, в Москве, Санкт-Петербурге, Томске, Краснодаре и других научных центрах.

Интерес представляет подход к анализу инновационной активности, который заключается в отнесении факторов к четырем типам: затраты на НИОКР, человеческий капитал, перетоки знаний и агломерационные эффекты Авторы этого подхода полагают, что одним из целевых индикаторов инновационной политики и зависимой переменной в будущих эмпирических исследованиях должно стать число международных патентов, так как выше качество их проверки и интенсивность коммерциализации в сравнении с национальными [3]. Существующие подходы к оценке результатов инноваций и эффективности работы организаций не лишен недостатков [4]. Можно отметить, что показатель «количество международных патентов» не всегда дает объективную оценку инновационной активности. Часть исследований и разработок могут быть засекречены и их результаты не всегда попадают в патентную статистику. Кроме того, существуют технологии фиктивного патентования, которые заключаются в организации защиты перспективных разработок, результат которых пока находится в сфере неопределенности. В последнее время сформировался бизнес по патентованию несуществующих в настоящее время продуктов и технологий, так называемых спящих патентов, владельцы которых осуществляют мониторинг рынка и инициируют судебные иски в момент появления похожего продукта или технологии [5].

В связи с этим, предлагается использовать в качестве результата инновационной деятельности показатель доли рынка продукции с высокой добавленной стоимостью [6]. Результатом космической деятельности считаются высокотехнологичные продукты и услуги, в которых велика http://ej.kubagro.ru/2017/08/pdf/59.pdf 
доля затрат на исследования и разработки и на приобретение инновационных технологий. Высокая конкуренция, которая наблюдается на мировом космическом рынке, служит своеобразным фильтром, отбирающий только максимально эффективные продукты и услуги, которые могут предоставить страны с высокоразвитой научной и производственной базой. Доля космического рынка, которую занимает страна, служит индикатором инновационной активности не только национальной РКП, но и всей экономической системы. Производство космической техники характеризуется высоким уровнем кооперации и инвестиции в предприятия РКП дадут положительный эффект в смежных областях - в приборостроении, металлургии, химической промышленности, а также в транспорте и связи. На инновационное развитие отечественной РКП оказывают внутренние и внешние факторы.

К внутренним факторам (In) отнесем:

- технологический $(T e)$;

- труда $(L)$;

- жизненного цикла $(L c)$.

К внешним факторам (Ex) относятся:

- конкуренция (Co);

- экономико-финансовые $(F)$;

- информационные (I);

- экологические $(E c)$.

Технологические факторы определяются наличием современных технологий, которыми обладает предприятие, тенденциям и в развитии технологических укладов, изменениями основных приоритетов в исследованиях и разработках. Для России важнейшими технологиями, определяющими конкурентоспособность всей космической деятельности, являются технологии радиационной защиты электронных приборов и солнечных батарей. 
Трудовые факторы, наряду с технологическими, оказывают определяющее значение на развитие и нормальное функционирование предприятий РКП. Квалификация работников, оплата труда, социальные гарантии повышают уровень развития человеческого каптала [7], задействованного в реализации космических проектов и программ, что делает более вероятной их успешную реализацию.

Фактор жизненного цикла можно считать самым важным из группы внутренних факторов. Определяющее значение в инновационном развитии играет стадия жизненного цикла, на которой находится каждое предприятие отечественной РКП. Изношенное оборудование, здания, сооружения, отсталые технологии требуют масштабных инвестиций в реконструкцию и обновление продукции, с другой стороны, вложение капитала в современное производство, выпускающее востребованную продукцию, может привести к снижению эффективности и потере устойчивости предприятия. Стадия жизненного цикла предприятия определяется уровнем общих средних издержек на выпуск единицы продукции [8]. На стадии внедрения новых видов продукции и технологий общие средние издержки начально находятся на достаточно высоком уровне, однако по мере наращивания выпуска снижаются до минимальных значений [9]. По мере износа основного и вспомогательного оборудования общие издержки начинают расти, что приводит к необратимым негативным последствия: предприятие теряет свою конкурентоспособность, вытесняется с рынка и прекращает свою деятельность - жизненный цикл предприятия на этом заканчивается. В качестве показателя жизненного цикла можно использовать уровень средних общих издержек на предприятии в сопоставимых ценах.

Экологические факторы в настоящее время становится все более значимыми для крупных предприятий, имеющих стратегическое значение для экономики страны. Практически во всем мире наблюдается тенденция http://ej.kubagro.ru/2017/08/pdf/59.pdf 
к повышению экологических стандартов и ужесточению наказания за их нарушение, что не может оказывать влияния на развитие инновационных видов деятельности, характерных на начальном этапе, высокими рисками. К экологическим факторам следует отнести глобальные и региональные изменения климата, а также загрязнение окружающей среды другими предприятиями. Влияние экологических факторов на РКП с каждым годом растет. Особое значение приобретает проблема космического мусора на орбите, ставящая под угрозу всю мировую космическую деятельность.

Фактор научно-технической информации определяет доступ предприятия к результатам исследований и разработок, технологическим лицензиям, новым знаниям и методам организации производственных процессов. Современные информационные технологии позволяют существенно ускорить производственный процесс, повысить производительность и качество выпускаемой продукции и услуг [10].

Конкуренция на местных и мировых рынках космической техники и услуг является важным фактором, определяющим вектор развития предприятия РКП. Конкуренция на местных рынках позволяет заказчику отбирать наиболее эффективные технические решения для реализации космических проектов. Обострение конкуренции на мировых космических рынках мотивирует предприятия модернизировать технологический процесс, снижать себестоимость производства, обновлять номенклатуру продукции и услуг.

Финансово-экономические факторы оказывают существенное влияние на функционирование исследовательских и промышленных предприятий РКП. Стабильное финансирование позволяет осуществлять долгосрочное планирование отрасли и накапливать научно-технический потенциал для реализации стратегических проектов. Сбои в финансировании приводят не только к потере темпов развития, но и к 
увеличению аварийности запусков, снижению эффективности системы аварийного спасения космического аппарата и другим проблемам.

Модель инновационного развития национальной РКП можно представить в виде:

$Y=\sum_{i=1}^{n} Y i$,

где $Y$ - уровень инновационного развития, измеряемый в общей доле мирового космического рынка, $Y_{i}-i$-сегмент мирового космического рынка (услуги запуска, космическая связь, навигация и т.п.), контролируемого отечественной РКП. На предприятия, участвующие в космических проектах, оказывают влияния внутренние и внешние факторы. Объем инновационной продукции и услуг, выпускаемых на мировой космический рынок, зависит от сочетания специфических внутренних и внешних факторов, характерных для определенного предприятия, функционирующего в рамках данного сегмента рынка. Модель инновационного развития для каждого предприятия РКП будет выглядеть:

$Y_{i}=f(\operatorname{In}, E x)$

или:

$Y i=f(T e, L, L c, C o, F, I, E c)$.

Для предприятий РКП, производящих средства запуска - ракетыносители (РН) и разгонные блоки (РБ) - критичными будут являться экологические факторы, в то время, как для спутниковой связи важными являются технологии радиационной защиты электронных приборов и солнечных батарей. Для нормального функционирования и развития наземной инфраструктуры (оборудование космодромов, станции слежения, центры управления и др.), критичным будет совершенно иной набор факторов, чем для предприятий РКП, выпускающих комплектующие для искусственных спутников Земли (ИСЗ). Влияние факторов на 
инновационное развитие предприятия, а также их взаимосвязь показаны на графической модели, изображенной на рис. 1.

Модель (рис. 1) показывает, что внутренние факторы (труд и технологии) обеспечивают инновационный рост предприятия в случае соответствия стадии жизненного цикла продукции и жизненному циклу предприятия. Здания и сооружения предприятия, основное и вспомогательное оборудование, инфраструктура должны соответствовать современному уровню применяемых технологий. Новые технологии должны соответствовать по своим параметрам инновационной продукции мирового технического уровня. Квалификация и компетенция работников должна соответствовать предъявляемым современными технологиями требованиям, а заработная плата на предприятиях РКП должна быть конкурентоспособной и более привлекательной, чем иные предложения на местных рынках труда. В этом случае предприятие сможет противостоять внешним вызовам и угрозам, формирующимся во внешней среде.

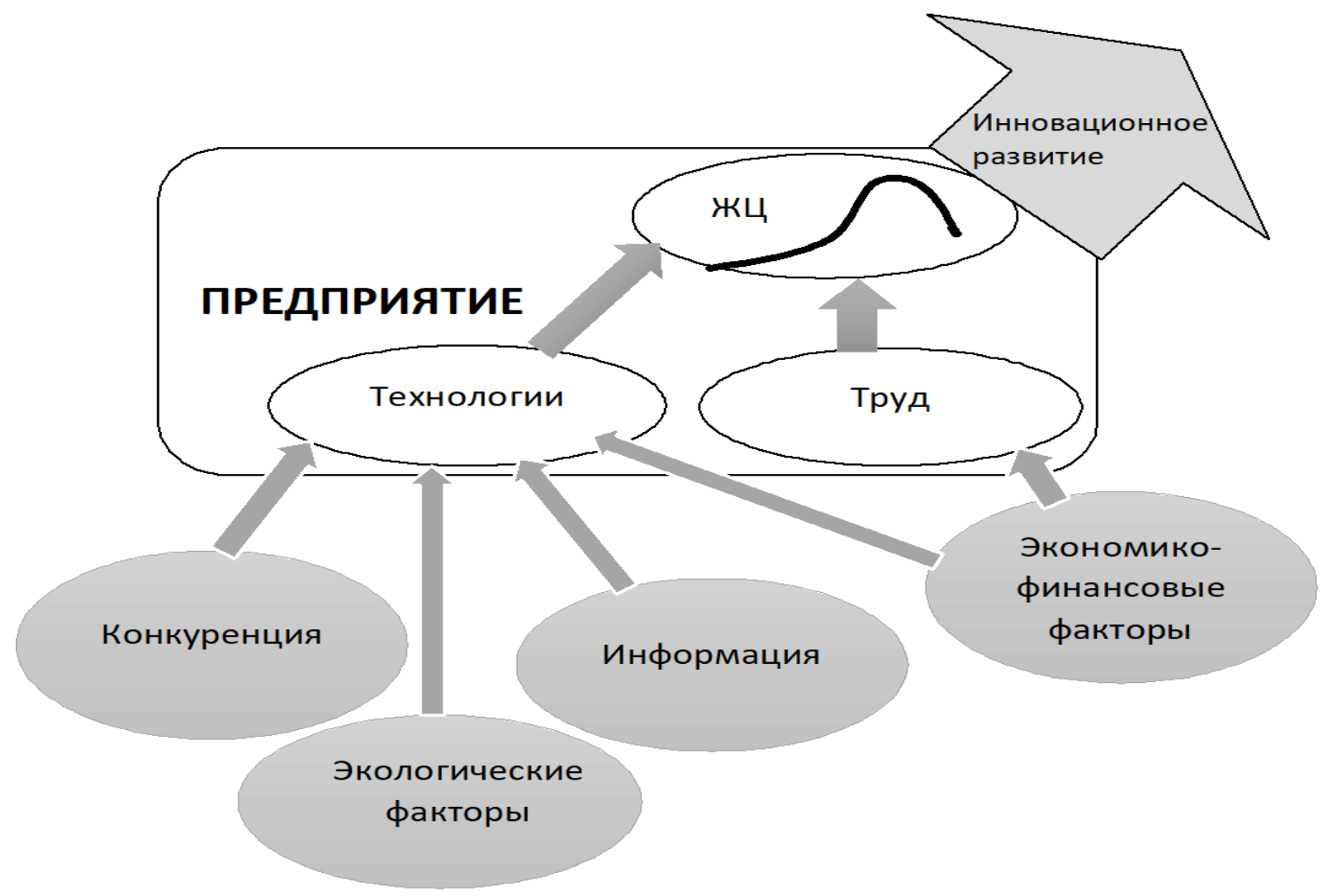

Рисунок 1. Модель инновационного развития предприятия РКП http://ej.kubagro.ru/2017/08/pdf/59.pdf 
Факторы внешней среды, как правило, оказывают негативное, хотя и не враждебное влияние на развитие предприятия. Так, конкуренция, экологические, финансово-экономические и другие факторы не ставят своей целью усугубить положение конкретного предприятия. Исключение составляют антироссийские экономические санкции, направленные против конкретных предприятий оборонно-промышленного комплекса.

Формально модель инновационного развития (5) предприятия РКП можно представить в виде:

$Y i=A(I n-E x)$,

где $A$ - коэффициент пропорциональности.

Устойчивый инновационный рост предприятия может быть обеспечен выполнением условия:

$\frac{d I n}{d t}=\frac{d E x}{d t}$,

где $t$ - время (долгосрочный период планирования, равный циклу действия программы инновационного развития).

Ускорение роста возможно при соблюдении условия:

$\frac{d I n}{d t} \geq \frac{d E x}{d t}$

однако, в этом случае могут существенно вырасти издержки и, возможно, формирование технологического дисбаланса в развитии отрасли.

Модель инновационного развития предприятия можно представить в виде модифицированной производственной функции Кобба-Дугласа:

$Y=A \cdot T e^{d} \cdot L^{r} \cdot L c^{k} \cdot C o^{m} \cdot F^{f} \cdot I^{n} \cdot E c^{e}$,

где $d, r, k, m, f, n, e-$ коэффициенты эластичности, или значимости каждого фактора в инновационном развитии предприятия. 
Для упрощения расчетов и определения коэффициентов, выражение (10) можно представить в виде натурального логарифма:

$\ln Y=\ln A+d \cdot \ln T e+r \cdot \ln L+k \cdot \ln L c+m \cdot \ln C o+f \cdot \ln F+n \cdot \ln I+e \cdot \ln E c ;(11)$

Численные значения коэффициентов эластичности и факторов модели могут быть получены методом экспертных оценок, инновационное развитие предприятий РКП измеряется в изменении доли, занимаемой продукцией предприятия на мировом рынке. В исследовании применялись коллективные экспертные оценки методом «Дельфи». В ходе опроса эксперты (5 чел.) оценивали уровень влияния факторов по десятибалльной шкале, минимальное влияние на развитие направления РКП оценивался в 1 балл, максимальное влияние - 10 баллов. Результаты опроса экспертов были статистически обработаны путем исключения наименьших и максимальных значений, полученные средние оценки были приняты для анализа. Обладая соответствующей базой данных по предприятию и по отрасли в целом, для расчетов модели можно использовать и численные значения. Экспертные оценки факторов влияния на инновационное развитие предприятий РКП приведена в табл. 1. 
Таблица 1

Оценка факторов влияния на инновационное развитие предприятий РКП России за 20014-2016 г.г.

\begin{tabular}{|c|c|c|c|c|c|c|c|}
\hline \multirow{3}{*}{$\begin{array}{l}\text { Направления } \\
\text { космической } \\
\text { деятельности }\end{array}$} & \multicolumn{7}{|c|}{ Факторы влияния } \\
\hline & \multicolumn{3}{|c|}{ Внутренние } & \multicolumn{4}{|c|}{ Внешние } \\
\hline & 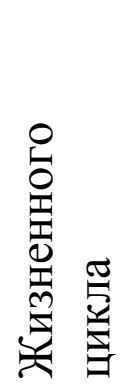 & 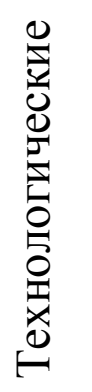 & 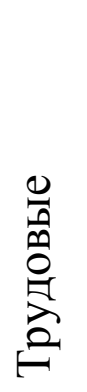 & 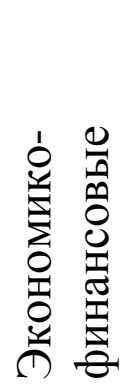 & 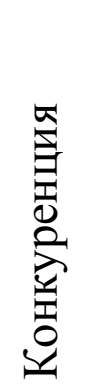 & 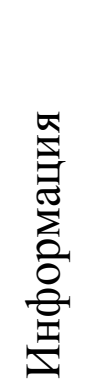 & 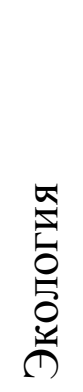 \\
\hline $\begin{array}{l}\text { Средства и услуги } \\
\text { запуска }\end{array}$ & 7,6 & 7,2 & 7,6 & 9,6 & 5,6 & 6,8 & 8,5 \\
\hline Производство ИСЗ & 7,5 & 9,2 & 8,1 & 9,4 & 8,6 & 9,2 & 6,5 \\
\hline $\begin{array}{l}\text { Производство } \\
\text { наземной техники }\end{array}$ & 8,5 & 7,5 & 5,2 & 8,5 & 9,2 & 8,5 & 3,2 \\
\hline Услуги связи, вещания & 3,5 & 5,2 & 6,5 & 6,2 & 8,4 & 9,2 & 2,5 \\
\hline
\end{tabular}

Анализ экспертных оценок показывает, что стадия жизненного цикла наиболее критична для производства наземной космической техники спутниковые антенны, ресиверы, станции обработки информации, мобильные устройства связи и т.д. Эти производства носят крупносерийный и массовый характер, где себестоимость изделий достаточно чутко реагирует на общее состояние технологического оборудования, а также зданий и сооружений. Изготовление спутников, а также систем запуска и вывода на орбиту, носит штучный, единичный характер, для таких технологий возможно некоторое несоответствие стадии жизненного цикла предприятия выпускаемой продукции. Для операторов связи и вещания, предоставляющих соответствующие услуги своим потребителям, жизненный цикл не является таким критичным. 
Технологические факторы оказывают максимально большое влияние на изготовление аппаратуры и платформ космических аппаратов. Критичными для развития отечественной РКП являются технологии защиты электронной аппаратуры и солнечных батарей от воздействия космических лучей. Новые технологии позволяют существенно повысить срок активного существования ИСЗ на орбите, повышают его производительность, точность измерений и другие важные для потребителей характеристики. Производство средств выведения космического аппарата орбиту нуждается в обновлении ракетных технологий, которые уже не удовлетворяют современным экологическим требованиям. Использование многоразовой космической техники позволяет снизить экологическую нагрузку и существенно удешевит услуги запуска для потребителя.

Наиболее наукоемким из направлений космической деятельности, можно считать производство ИСЗ, которое требует высокой квалификации работников исследовательских организаций и промышленных предприятий. Производство спутника связи занимает в среднем от полугода до полутора лет, его стоимость измеряется десятками и сотнями миллионов долларов, в которых большую часть занимает добавленная стоимость - труд и прибыль. ИСЗ - штучный продукт, каждый новый спутник, изготовленный на предприятии отличается от своего предшественника (исключение составляют группировки спутников, запускаемых одновременно для организации связи, навигации и др.) Именно в этой сфере фактор труда играет максимально важное значение. В ракетостроении этот фактор играет меньшее значение, так как производство РН и РБ носит серийный характер и часть технологических операций автоматизированы, высокая квалификация здесь не так востребована, как в производстве ИСЗ. Оказание услуг связи и вещания в настоящее время осуществляется посредством информационных 
технологий, специалисты заняты в основном в сфере устранения сбоев в работе систем, консультации пользователей и на других работах, не предъявляющих исключительных требований к работникам.

Экономико-финансовые факторы оказывают существенное влияние практически на все виды космической деятельности. Космическая деятельность характерна высокими затратами на проведение исследований и разработок, испытаний космической техники, ее изготовление и эксплуатацию в околоземном пространстве. Особенно чувствительны к этим факторам производства, занятые изготовлением ИСЗ, РН и РБ и другой космической техники, работающей в открытом космосе. Изменение условий кредитования, курсов валют и другие финансовые риски могут существенно повлиять не только на сроки реализации проектов, но и на аварийность космической техники. Так, финансовый кризис 2008-2010 г. г. привел к сбоям финансирования космических проектов, в результате чего уже в 2011 г. произошло несколько серьезных аварий на стадии запуска и выведения на орбиту дорогих космических аппаратов.

Конкуренция возникает в тех сегментах космической деятельности, где для производителей есть относительно легкий доступ к ресурсам, присутствуют несущественные барьеры для входа на рынок и имеется множество независимых потребителей. Современный уровень развития космических технологий позволяет различным странам запускать собственные спутники, которые изготавливаются и продаются несколькими независимыми производителями. Ракетные технологии доступны пока только узкой группе стран, в число которых входит и Россия. На рынке пусковых услуг конкуренция не такая острая, как на рынках наземной космической техники или услуг. Для России критичным является недостойно низкое место в сфере производства коммерческих ИСЗ и на рынке услуг космической связи и вещания, откуда отечественную РКП выбили конкуренты из США, КНР и стран Евросоюза. 
Информация, как фактор инновационного развития РКП, играет определяющую роль в космической деятельности. Особенно чувствительны к этому фактору продукты и услуги с относительно коротким жизненным циклом, к которым можно отнести наземную мобильную технику для космической связи, антенны, ресиверы и другая аппаратура приема и передачи данных. Новые технологии и продукты появляются благодаря обмену, переработке и анализу научно-технической информации, поступающей из разных источников. Колоссальные ресурсы международные и национальные корпорации расходуют на защиту собственной и получение чужой информации о направлениях исследований, результатах реализации проектов, новых технологиях и других объектах космической деятельности. Особое значение информация имеет для наиболее наукоемкого направления космической деятельности изготовление орбитальной и наземной космической техники. Оказание услуг космической связи и вещания, мониторинга земной поверхности и навигации невозможно без поддержки информационных технологий, поэтому этот фактор играет большую роль в данном сегменте космической деятельности.

Экологический фактор оказывает существенное давление на производство и услуги запуска. Современные технологии запуска космического аппарата предусматривают, как побочный эффект, загрязнение окружающей среды ракетным топливом и частями ракет, которые наносят экологический ущерб при падении на земную (водную) поверхность. Особую значимость приобретает проблема космического мусора в околоземном пространстве, загрязненным обломками пришедших в негодность спутников, частей разгонных блоков и последних ступеней PH. В ближайшее десятилетие экологические факторы могут существенно повлиять на космическую активность практически всех стран мира.

Рассмотренные выше факторы носят постоянный характер, характерны для различных экономических систем и периодов. Вместе с 
тем, существует группа политических факторов, которые носят случайный, непредсказуемый характер и с трудом поддаются прогнозированию. Отдельные страны, в разное время, с целью сдерживания развития других государств, вводили экономические санкции, активизируя часть рассмотренных выше факторов.

В табл. 2 приведены основные методы сдерживания развития экономических систем.

Таблица 2

\section{Результат активизации факторов сдерживания}

\begin{tabular}{|c|c|c|c|}
\hline $\begin{array}{l}\text { Направления } \\
\text { сдерживания }\end{array}$ & Методы сдерживания & $\begin{array}{c}\text { Ожидаемый результат для } \\
\text { инициаторов санкций }\end{array}$ & $\begin{array}{c}\text { Возможный результат в } \\
\text { стране }\end{array}$ \\
\hline \multirow{3}{*}{ 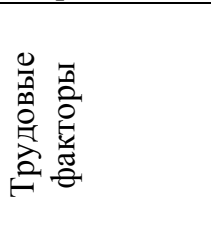 } & \multirow[t]{2}{*}{$\begin{array}{l}\text { Введение визового } \\
\text { режима }\end{array}$} & $\begin{array}{l}\text { Осложнения при заключении } \\
\text { международных контрактов }\end{array}$ & $\begin{array}{l}\text { Возможность заключения } \\
\text { внутренних контрактов }\end{array}$ \\
\hline & & $\begin{array}{l}\text { Затруднение выполнения } \\
\text { действующих контрактов }\end{array}$ & $\begin{array}{l}\text { Возможность привлечение } \\
\text { местной рабочей силы }\end{array}$ \\
\hline & $\begin{array}{l}\text { Запрет на работу в } \\
\text { стране специалистов }\end{array}$ & $\begin{array}{l}\text { Осложнения в реализации } \\
\text { проектов }\end{array}$ & $\begin{array}{l}\text { Снижение вероятности утечки } \\
\text { информации }\end{array}$ \\
\hline \multirow{8}{*}{ 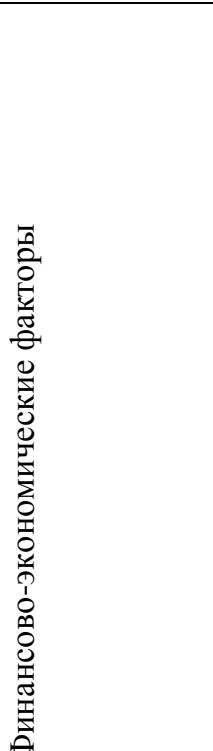 } & $\begin{array}{l}\text { Прекращение } \\
\text { финансирования } \\
\text { инвестиционных } \\
\text { проектов в стране } \\
\end{array}$ & $\begin{array}{l}\text { Осложнения в реализации } \\
\text { проектов }\end{array}$ & $\begin{array}{l}\text { Снижение зависимости от } \\
\text { иностранного капитала }\end{array}$ \\
\hline & \multirow{3}{*}{$\begin{array}{l}\text { Ограничения в доступе } \\
\text { к международному } \\
\text { рынку ссудных } \\
\text { капиталов для страны }\end{array}$} & $\begin{array}{l}\text { Удорожание проектов, } \\
\text { осложнения в их реализации }\end{array}$ & $\begin{array}{l}\text { Возможность оптимизации } \\
\text { финансирования }\end{array}$ \\
\hline & & Рост процентных ставок & \multirow{2}{*}{$\begin{array}{l}\text { Независимость от } \\
\text { международного рынка } \\
\text { ссудных капиталов }\end{array}$} \\
\hline & & $\begin{array}{l}\text { Отток капитала (валюты) из } \\
\text { страны }\end{array}$ & \\
\hline & $\begin{array}{l}\text { Ограничение } \\
\text { финансовых } \\
\text { грансакций } \\
\end{array}$ & $\begin{array}{l}\text { Замедление оборота, снижение } \\
\text { производительности }\end{array}$ & $\begin{array}{l}\text { Создание собственного } \\
\text { клирингового центра }\end{array}$ \\
\hline & \multirow{3}{*}{$\begin{array}{l}\text { Ограничения на } \\
\text { прямые инвестиции в } \\
\text { страну }\end{array}$} & Снижение производства в стране & $\begin{array}{l}\text { Снижение зависимости от } \\
\text { иностранного капитала }\end{array}$ \\
\hline & & $\begin{array}{l}\text { Снижение поступления валюты в } \\
\text { страну }\end{array}$ & \multirow[t]{2}{*}{ Снижение оттока капитала } \\
\hline & & $\begin{array}{l}\text { Снижение } \\
\text { конкурентоспособности страны }\end{array}$ & \\
\hline$\theta$ & \multirow{4}{*}{$\begin{array}{l}\text { Запрет на } \\
\text { международные } \\
\text { контракты }\end{array}$} & $\begin{array}{l}\text { Сокращение доли мирового } \\
\text { рынка }\end{array}$ & \multirow[t]{4}{*}{$\begin{array}{l}\text { Переориентация на местные } \\
\text { рынки }\end{array}$} \\
\hline & & $\begin{array}{l}\text { Снижение } \\
\text { конкурентоспособности страны }\end{array}$ & \\
\hline & & Снижение притока валюты & \\
\hline & & Сокращение производства & \\
\hline \multirow{3}{*}{ 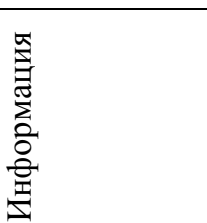 } & \multirow{2}{*}{$\begin{array}{l}\text { Запрет на доступ к } \\
\text { технологиям и базам } \\
\text { данных }\end{array}$} & $\begin{array}{l}\text { Снижение конкурентно - } \\
\text { способности страны }\end{array}$ & \multirow{3}{*}{$\begin{array}{l}\text { Активизация внутренних } \\
\text { научных исследований и } \\
\text { разработок }\end{array}$} \\
\hline & & Сокращение производства & \\
\hline & $\begin{array}{l}\text { Запрет на проведение } \\
\text { НИР }\end{array}$ & $\begin{array}{l}\text { Осложнения в проведении } \\
\text { научных исследований }\end{array}$ & \\
\hline
\end{tabular}


Введение экономических санкций оказывает влияние прежде всего на трудовые, экономико-финансовые и информационные факторы. Запрет на движение капитала, информации и рабочей силы не только угрожает развитию системы, но и существенно усложняет нормальное функционирование промышленных предприятий и научных организаций.

Всего ООН вводило санкции против 20 государств, включая Иран, Ирак, Югославию. США до сих пор продолжает блокаду Кубы, против России с 2014 г. действуют ограничения ЕС, США и некоторых других государств. Можно отметить, что те страны, которые имели определенный научный задел, смогли выдержать санкционное давление и добиться впечатляющих результатов. Так, несмотря на санкции, КНДР и Иран добились весьма впечатляющих успехов в реализации своих ядерных и космических программ, Россия по-прежнему занимает лидирующее положение на рынке вооружений и в космосе, хотя ограничение поставок некоторых электронных приборов, используемых в ракетно-космической и оборонной промышленности оказалось весьма болезненным для России. Как заметил руководитель Конструкторского бюро точного электронного машиностроения (ОАО «КБТЭМ-ОМО») Владимир Зуев «...западные транзисторы, микросхемы, интегральные схемы в производстве российского вооружения составляют до 90\%» [11]. Исторический опыт показывает, что попытки экономической изоляции России активизировали еe инновационный потенциал и в этот период страна добивалась значительных успехов в различных направлениях науки и техники.

В 2016 г. Россия заработала 1678 млн. долл. США, что составило менее процента $(0,64 \%)$ мирового космического рынка, оцениваемого за тот период в 260,5 млрд. долл. США . Вполне возможно, в статистику не

\footnotetext{
${ }^{1}$ По данным ECORUSPACE.ME развитие мирового рынка космических продуктов и услуг в 2016 году. Москва, 2017 г. [Электронный ресурс] URL: http://ecoruspace.me/\%D0\%A0\%D1\%8B\%D0\%BD\%D0\%BE\%D0\%BA+\%D0\%94\%D0\%97\%D0\%97.html. Дата обращения 16.09.2017 г.

http://ej.kubagro.ru/2017/08/pdf/59.pdf
} 
вошли запуски российских спутников по военным программам, но даже с учетом этой поправки, доля России на порядки ниже, чем США, КНР и стран ЕС, хотя в отдельных секторах космического рынка Россия уверено держит 20-30\% (услуги запуска и выведения на орбиту космических аппаратов).

Научный и производственный потенциал отечественной РКП позволяет в кратчайшие сроки занять не менее $15 \%$ мирового рынка космических услуг, не менее $10 \%$ на рынке орбитальной и наземной космической техники.

Для ликвидации отставания отечественной РКП от современных тенденций мирового космического рынка необходимо сформировать программу инновационного развития отрасли и ее ведущих предприятий с учетом всех основных факторов влияния.

\section{Литература}

1. Инновационный потенциал научного центра: Методологические и методические проблемы анализа и оценки / отв. ред. В.И. Суслов. - Новосибирск: ИЭОПП, 2007. $275 \mathrm{c}$

2. Штерцер Т. А. Эмпирический анализ факторов инновационной активности в субъектах РФ // Вестник Новосибирского государственного университета. Серия: Социально-экономические науки. 2005. Т. 5.№. 2. С. 100.

3. Земцов С. П., Баринова В. А., Мурадов А. К. Факторы региональной инновационной активности: анализ теоретических и эмпирических исследований // Инновации. 2016. № 5. С. 41-51.

4. Барановская Т.П., Вострокнутов А.Е. Модели совершенствования и оценки организационных структур // Политематический сетевой электронный научный журнал КубГАУ. 2008. № 36. С. 61-76.

5. Хрусталёв Е. Ю., Славянов А. С. Особенности применения зарубежного опыта защиты интеллектуальной собственности при формировании национальной инновационной стратегии // Экономический анализ: теория и практика. 2017. Т. 16. Вып. 4. С. 665-676.

6. Хрусталёв Е.Ю., Славянов А. С. Инновационно-ориентированная методология оценки состояния и возможностей роста национальной экономической системы // Политематический сетевой электронный научный журнал Кубанского государственного аграрного университета. 2016. № 115. С. 98-116.

7. Славянов А. С. Проблемы совершенствования оплаты труда на предприятиях наукоемкого сектора российской экономики // Контроллинг. 2016. № 3. С. 28-33.

8. Славянов А. С. Жизненный цикл как основа формирования инновационной и инвестиционной стратегии предприятия // Аудит и финансовый анализ. 2017. № 2. С. 308-314. 
9. Славянов А. С. Поддержка принятия управленческих решений в период проведения инновационной модернизации производства на основе модели жизненного цикла предприятия // Контроллинг. 2017. № 1. С. 26-31.

10. Барановская Т.П., Лойко В.И., Семенов М.И., Трубилин И.Т. Информационные системы и технологии в экономике. - М.: Финансы и статистика, 2003. $416 \mathrm{c}$.

11. Зуев В. Ученые: в российском вооружении до $90 \%$ западной электроники // Материалы семинара «Научно-техническая и промышленная интеграция: стандарты и эталоны Союзного государства» 29.10.2014 электронный ресурс газета.ru. http://www.gazeta.ru/science/news/2014/10/31/n_6611725.shtml

12. Romer P. M. Increasing returns and long-run growth // The journal of political economy. 1986. No. 23. P. 1002-1037.

13. Crescenzi, Riccardo and Alexander Jaax. Innovation in Russia: the territorial dimension // Economic Geography. 2015. No. 1509. P. 131-149.

14. Jaffe A. B. Real effects of academic research // The American Economic Review. 1989. No. 7. P. 957-970.

\section{References}

1. Innovacionnyj potencial nauchnogo centra: Metodologicheskie i metodicheskie problemy analiza i ocenki / otv. red. V.I. Suslov. - Novosibirsk: IJeOPP, 2007. 275 s

2. Shtercer T.A. Jempiricheskij analiz faktorov innovacionnoj aktivnosti v sub\#ektah RF // Vestnik Novosibirskogo gosudarstvennogo universiteta. Serija: Social'nojekonomicheskie nauki. 2005. T. 5. №. 2. S. 100.

3. Zemcov S.P., Barinova V.A., Muradov A.K. Faktory regional'noj innovacionnoj aktivnosti: analiz teoreticheskih i jempiricheskih issledovanij // Innovacii. № 5. 2016. S. 4151.

4. Baranovskaya T.P., Vostroknutov A.E. Modeli sovershenstvovaniya i ocenki organizacionnyh struktur // Politematicheskij setevoj ehlektronnyj nauchnyj zhurnal KubGAU. 2008., № 36. S. 61-76.

5. Khrustalev E.Yu., Slavjanov A.S. Innovacionno-orientirovannaja metodologija ocenki sostojanija i vozmozhnostej rosta nacional'noj jekonomicheskoj sistemy // Politematicheskij setevoj jelektronnyj nauchnyj zhurnal Kubanskogo gosudarstvennogo agrarnogo universiteta, 2016. № 115. S. 98-116.

6. Khrustalev E.Yu., Slavjanov A.S. Osobennosti primenenija zarubezhnogo opyta zashhity intellektual'noj sobstvennosti pri formirovanii nacional'noj innovacionnoj strategii// Jekonomicheskij analiz: teorija i praktika 2017. T. 16. Vyp. 4. S. 665-676.

7. Slavjanov A.S. Problemy sovershenstvovanija oplaty truda na predprijatijah naukoemkogo sektora rossijskoj jekonomiki // Kontrolling. 2016. № 3. S. 28-33

8. Slavjanov A.S. Zhiznennyj cikl kak osnova formirovanija innovacionnoj i investicionnoj strategii predprijatija // Audit i finansovyj analiz. 2017. № 2. S. 308-314.

9. Slavjanov A.S. Podderzhka prinjatija upravlencheskih reshenij $\mathrm{v}$ period provedenija innovacionnoj modernizacii proizvodstva na osnove modeli zhiznennogo cikla predprijatija // Kontrolling. 2017. № 1. S. 26-31.

10. Baranovskaya T.P., Lojko V.I., Semenov M.I., Trubilin I.T. Informacionnye sistemy i tekhnologii v ehkonomike. - M.: Finansy i statistika, 2003. $416 \mathrm{~s}$.

11. Zuev V. Uchenye: v rossijskom vooruzhenii do $90 \%$ zapadnoj jelektroniki // Materialy seminara «Nauchno-tehnicheskaja i promyshlennaja integracija: standarty i jetalony Sojuznogo gosudarstva» 29.10.2014 jelektronnyj resurs gazeta.ru. 
12. Romer P.M. Increasing returns and long-run growth // The journal of political economy. 1986. No. 23. P. 1002-1037.

13. Crescenzi, Riccardo and Alexander Jaax. Innovation in Russia: the territorial dimension // Economic Geography. 2015. No. 1509. P. 131-149.

14. Jaffe A. B. Real effects of academic research // The American Economic Review. 1989. No. 7. P. 957-970. 